\title{
DE LAS AFROASCENDENCIAS A LA AFRODESCENDENCIA. REFLEXIONES SOBRE ÁMBITO, MÉTODOS Y APLICACIONES DE LA ETNOHISTORIA AFRO- VENEZOLANA
}

FROM AFROASCENDENCIAS TO AFRODESCENDENCIA. SOME REFLECTIONS ABOUT DELIMITATION, METHODS AND APPLICATIONS IN AFROVENEZUELAN ETHNOHISTORY.

Pedro Rivas

Como citar este artigo:

RIVAS, Pedro. De las afroascendencias a la afrodescendencia. Reflexiones sobre ámbito, métodos y aplicaciones de la etnohistoria afrovenezolana. Cadernos do Lepaarq, v. XVII, n.33, p. 182-196, Jan-Jun. 2020.

Recebido em: 14/12/2019

Aprovado em: 08/04/2020

Publicado em: 09/05/2020 


\title{
De las afroascendencias a la afrodescendencia. Reflexiones sobre ámbito, métodos y aplicaciones de la etnohistoria afrovenezolana
}

\author{
Pedro Rivas ${ }^{\text {a }}$
}

Resumen: Después de hacer una revisión de antecedentes en publicaciones especializadas, este trabajo expone ideas sobre el tema de la etnohistoria afrovenezolana. Se presentan algunos conceptos acerca de su delimitación y aplicaciones desde el enfoque interdisciplinario, utilizando como ejemplo el Proyecto Antropología de la Parroquia Caruao.

\section{Palabras Clave:}

Etnohistoria, Afrovenezolanos, Diversidad étnica, Métodos interdisciplinarios, Venezuela.

\begin{abstract}
After a review of the antecedents in specialized publications, this study presents ideas concerning the topic of afrovenzuelan ethnohistory. In addition it proposes several concepts with respect to the delimitation and applications from the interdisciplinary perspective, using as an example the Proyecto Antropología de la Parroquia Caruao (english: Anthropology of the Caruao Parish Project).
\end{abstract}

Keywords:

Ethnohistory, Afrovenezuelans, Ethnic diversity, Interdisciplinary methods, Venezuela.

\footnotetext{
a Instituto Caribe de Antropología y Sociología, Fundación La Salle de Ciencias Naturales, Caracas, Venezuela. Email: pjrivasgomez@gmail.com
} 


\section{ALGUNOS ANTECEDENTES}

Dentro del panorama de las investigaciones etnohistóricas publicadas en Venezuela por profesionales de la antropología ${ }^{1}$, no deja de llamar la atención que el estudio diacrónico y singular de los diferentes componentes de origen africano sigue siendo incipiente, pese a que se cuenta con importantes reflexiones pioneras que se remontan a la primera mitad del siglo XX, más una copiosa bibliografía que, aunque es fundamentalmente de naturaleza etnográfica y etnológica, a veces incluye ciertas consideraciones acerca del origen de ciertos elementos culturales, los procesos históricos que explicarían la incorporación de este gran conjunto de pobladores al actual territorio nacional y los contextos económicos, sociales y políticos bajo los cuales se fue insertando. Se dispone, además, de importantes fondos documentales manuscritos y notables colecciones de referencia africanas y americanas en distintos formatos.

Aún así, el tema sigue siendo insuficientemente abordado en comparación con la producción de distintos especialistas del área de la historia o de la educación, como José Marcial Ramos Guédez, Jesús García, Juan de Dios Martínez, Miguel Ángel Ortega, Jesús Blanco Sojo, Marcos Andrade Jaramillo, Ricardo Castillo Hidalgo o José Bracho Reyes, entre otros, cuyos aportes plantean la necesidad de reconocer la trascendencia antropológica de sus trabajos, independientemente de cuál haya sido su formación profesional o si emplearon teorías y metodologías distintas a las de la antropología. Similar reflexión hay que hacer a propósito de los estudios coordinados por Yolanda Salas (SALAS, GONZÁLEZ VILORIA, VELÁSQUEZ, 1987, p. 147, 240), que iniciaron la indagación de interpretaciones propias (émic) sobre los procesos históricos nacionales presentes en la memoria oral afrovenezolana de la zona de Barlovento. Los aportes de ese grupo de investigadores de alguna manera han cubierto un vacío en la antropología venezolana, que mayormente ha estado orientada a temas indígenas, o bien rurales y urbanos actuales no explícitamente centrados en la historia de la afrovenezolanidad. Esta limitación se agravó con el cierre de la Cátedra de Estudios Afroamericanos de la Escuela de Antropología de la Universidad Central de Venezuela que durante los años ochenta del siglo XX dirigió Michaelle Ascencio y había estimulado la formación de una nueva generación especializada en el área, aunque orientada más a temas contemporáneos, no de corte etnohistórico².

Si nos limitamos a la producción editorial antropológica formal, dentro del campo de la etnohistoria afrovenezolana habría que subrayar la obra de autores como Miguel Acosta Saignes (1967), quien, aparte de hacer estudios etnográficos y registros visuales de gran interés, abordó el tema de la esclavitud bajo una doble perspectiva, diacrónica y sincrónica, ensayando la reconstrucción

\footnotetext{
${ }^{1}$ El presente ensayo enfatiza en los estudios etnohistóricos o de etnología antigua enmarcados en teorías y metodologías antropológicas o realizados por especialistas de esta ciencia. Por limitaciones editoriales, al momento de examinar los antecedentes se optó por escoger algunos títulos de publicaciones que son ilustrativas de cada autor.

2 Además con escasa trascendencia editorial. Con la más reciente apertura de estudios de pregrado en antropología en la Universidad del Zulia, así como de postgrados en esa misma universidad, en la Universidad de Los Andes y en el Instituto Venezolano de Investigaciones Científicas, las obras con ese perfil podrían multiplicarse en un futuro.
} 
de aspectos de la vida cotidiana dentro de algunas unidades de producción coloniales, y llevó a cabo la primera clasificación etnolingüística de los distintos componentes africanos raíces, inspirado por los estudios de Gonzalo Aguirre Beltrán, en México, y de Fernando Ortiz, en Cuba. Más tarde Angelina Pollak-Eltz (1972, p. 25-32) procuró actualizar esa clasificación, ocupándose también en general de la esclavitud (Pollak-Eltz, 2000), pero además de la percepción del sí mismo (Pollak-Eltz, 1998), del reconocimiento de rasgos culturales de posible origen africano en comunidades afrovenezolanas o extendidas en gran parte del país, y del caso peculiar de los enclaves afroantillanos conformados en los estados Sucre y Bolívar.

Otros autores destacados han sido Federico Brito Figueroa (1973), antropólogo e historiador, con interpretaciones desde la perspectiva del materialismo histórico e influenciado por la escuela historiográfica francesa, y la antes mencionada Michaelle Ascencio (1984), quien, entre otros aspectos, discutió el posible origen trasatlántico de ciertas instituciones religiosas y desentrañó cómo operaba el código de nombramiento de los esclavos, sus "apellidos" registrados en censos y matrículas. Por otra parte, Acosta Saignes, primero, después Johannes Wilbert (1976), y luego Petra Josefina Moreno junto a Alberto Tarazona (1984), documentaron la formación de rochelas o cimarroneras (cumbes, quilombos) de composición étnica mixta (africana, wayúu e hispanocriolla) constituidas en la Península de La Guajira desde finales del siglo XVI, así como la posible huella que tal convivencia dejó en la biología y en la cultura material e inmaterial de los indígenas Wayúu actuales.

Aproximadamente contemporánea a los primeros ensayos de Acosta Saignes y de Brito Figueroa se inició una interesante línea de investigaciones seguida desde la óptica de la antropología física en la que se involucró Wilbert: la búsqueda de marcadores biológicos que señalen ascendencias africanas, información de gran utilidad en estudios etnohistóricos interdisciplinarios y de la cual Venezuela fue pionera gracias a los trabajos serológicos de Miguel Layrisse y Wilbert (1966), que de alguna manera ha tenido continuidad en nuestro tiempo en métodos de mayor complejidad aportados por la moderna antropología molecular, con la participación de Dinorah Castro, investigadora del Instituto Venezolano de Investigaciones Científicas y docente de la Escuela de Antropología de la Universidad Central de Venezuela (CASTRO DE GUERRA, ARROYO, SALZANO y CÁTIRA BORTOLINI, 2003; RODRÍGUEZ SARRALDE, CASTRO DE GUERRA, GONZÁLEZ y MORALES, 2001; SALAZAR LUGO, GONZÁLEZ, CASTRO-GUERRA y ARENDS, 2006). Hay que aclarar que inicialmente este tipo de estudios aprovechaba la detección de marcadores genéticos característicos de poblaciones africanas básicamente para indagar mestizaje entre etnias indígenas, colectividades en las que se centraban las investigaciones; más recientemente se aprovecharon para evaluar globalmente la diversidad genética del país, y solo últimamente se reorientó el interés para el estudio de colectividades afromestizas cuyos ancestros procedían del norte de África o de África subsahariana.

Durante las últimas décadas del siglo XX y lo que va del presente la exploración de las raíces históricas de comunidades afrovenezolanas en el contexto de estudios antropológicos se ha restringido a la producción de apartados específicos dentro de varias tesis de pregrado y de postgrado 
centradas en el análisis de poblaciones actuales, incluido el precursor trabajo de Alfredo Chacón, publicado luego como monografía (CHACÓN, 1979), o el de Yara Altez, de 1987, también llevado luego a la imprenta (ALTEZ, 1999), quien aborda con mayor profundidad los peculiares orígenes histórico-culturales de comunidades del presente utilizando como fuentes de información no solo la documentación escrita sino también el estudio de la memoria oral y la genealogía. Desde los tiempos de su investigación pionera, hacia 1985, Altez inició una línea de estudios que ha mantenido hasta la actualidad bajo la forma de dos proyectos eslabonados de investigación auspiciados por el Consejo de Desarrollo Científico y Humanístico de la Universidad Central de Venezuela: el Proyecto Mismidad del Sabanero, y el Proyecto de Antropología de la Parroquia Caruao. Adscritos al Departamento de Teoría y Métodos de la Escuela de Antropología de esa universidad, ambos proyectos han explorado la utilización de diferentes fuentes de información en el estudio diacrónico de comunidades ubicadas en la parroquia más oriental del estado Vargas, región norcentral del país, fronteriza-e históricamente interconectada- con los importantes enclaves afrovenezolanos de la región de Barlovento. Desde el año 1994 se incorporó un componente de investigación arqueológica, sobre el cual ya se ha hecho referencia (ALTEZ y RIVAS 2002; 2015), y a partir del año 2003, el uso de cartografía histórica y de aerofotografía antigua, con el fin de estudiar cambios locales en los patrones de asentamiento, en el aprovechamiento de los recursos naturales, o en la comunicación terrestre entre comunidades vecinas. El estudio de la interdependencia de variables culturales y ambientales explorado por estos proyectos ha contado también con la asesoría ocasional de especialistas en geología, antropología y agronomía de la Fundación Venezolana de Investigaciones Sismológicas, de la Escuela de Geología de la Universidad Central de Venezuela y del antiguo Ministerio del Ambiente y de los Recursos Naturales Renovables.

Otros estudios de interés etnohistórico se han venido realizando también en centros de docencia e investigación ubicados en la Universidad de Los Andes, en la Universidad de Oriente, en la Universidad de Carabobo, en la Universidad Simón Bolívar (HERRERA SALAS, 2003), en la Universidad del Zulia, así como en el Instituto Venezolano de Investigaciones Científicas. En el último ente mencionado se han llevado a cabo trabajos de especial significación, bien sea a propósito de la ya mencionada trascendencia histórica de ciertos hallazgos en antropología molecular, o bien del tema de la formación y continuidad de enclaves con descendientes de esclavos cimarrones en el norte del país (GUERRA CEDEÑO, 1984), y en la región de Guayana, estos últimos bajo la coordinación de la investigadora Berta Pérez (PÉREZ, 1995).

A nuestro juicio, los estudios realizados por la Universidad Central de Venezuela y por el Instituto Venezolano de Investigaciones Científicas constituyen ejemplos de una metodología aplicable en etnohistoria afrovenezolana, con énfasis en un enfoque interdisciplinario y -en lo posible- en el establecimiento de posibles conexiones entre las poblaciones del pasado y las del presente, vía que favorece no sólo una visión holística de su historia sino también el trasvase local de la información y la apropiación social final del conocimiento generado. El desarrollo de nuevos proyectos y equipos de investigación en este línea podría estimularse si se superan obstáculos tales 
como la indefinición del sujeto de estudio y, por lo tanto, del ámbito de la etnohistoria afrovenezolana, delimitación que dependerá de cuán claro se esté acerca de la diversidad interna de ese colectivo en sus orígenes, así como de sus singularidades frente al conjunto de la población del país u otras comunidades afroamericanas.

\section{Diversidad interna y escalas de diferenciación}

La relativa ausencia de publicaciones antropológicas explícitamente identificadas con el campo de la etnohistoria afrovenezolana en parte es el resultado de cierta vaguedad en cuanto a la competencia de esta disciplina en el abordaje de poblaciones consideradas genética y culturalmente mestizas, de la dificultad o inconveniencia -por esa misma razón- de distinguir un área específica de estudios que subraye la categoría etnia dentro de campos de la antropología e historia venezolana afines o más amplios, pero quizás también ha sido motivada por la zigzagueante trayectoria que ha tenido el reconocimiento de la diversidad interna de ese gran conjunto demográfico. Y es que desde los inicios mismos de la reflexión histórica y antropológica venezolana sobre esas poblaciones parecen apreciarse dos modalidades de discurso que se alternan entre autores y momentos históricos, que unas veces simplifican el tema y otras veces lo revisten de gran complejidad. La primera modalidad, homogeneizadora, aludía genéricamente a un componente "negro" o "africano" en la población venezolana, y llegó a influir en la redacción de textos educativos así como en la producción de programas divulgativos en los medios de comunicación social, no pocas veces asociados a estereotipos culturales negativos; la otra reconoce o subraya distinciones internas así como en comparación a poblaciones afroamericanas de otros países del gran Caribe o de las Guayanas, pero se ha restringido a textos especializados y por ello su difusión ha sido más limitada. Es posible percibir cierto desinterés derivado de la supuesta uniformidad cultural proclamada en lo primero, o de la dificultad de aprehenderlo según lo segundo. Una posición intermedia entre ambas modalidades discusivas es la sobrevaloración de algunos componentes étnicos africanos específicos sobre otros, razonablemente sustentada al principio en datos históricos, lingüísticos y etnográficos (presencia Benue-Congo Bantuoide), pero más recientemente también, de manera un tanto arbitraria, por influencias políticas y culturales foráneas coyunturales antillanas (rasgos VoltaNiger Yoruboides) sugiriendo esto similitudes en los procesos históricos de países como Venezuela y Cuba, lo cual es inexacto.

En realidad, ambos discursos son simplificadores de la heterogeneidad histórica, cultural -y hasta biológica- interna de las poblaciones afrovenezolanas, pues coinciden en restringir el aporte demográfico a las comunidades subsaharianas incorporadas durante la trata de esclavos, ignorando o subestimando a otros componentes africanos que penetraron bajo ese $u$ otros contextos: esclavos "blancos", moriscos, guanches y berberiscos (durante la primera mitad del siglo XVI), inmigrantes canarios (sobre todo desde el siglo XVIII), inmigrantes sefardíes marroquíes (fundamentalmente a partir de las últimas décadas del sigloXIX y principios del XX), o comunidades afroamericanas de las islas 
del Caribe (finales del siglo XVIII a siglo XX) que aunque sí tienen un origen subsahariano y vinculado a la trata de esclavos, entran al país más tardíamente como pequeños comerciantes costeños, o como peones, obreros y operarios al servicio de empresarios de origen europeo-antillano, europeo o estadounidense. Hay que considerar, además, a los descendientes de cimarrones huidos de las antiguas colonias holandesas e inglesas del Esequibo y de las antiguas Antillas neerlandesas, o a la progenie de inmigrantes de más reciente data, procedentes de otros puntos de nuestro continente y hasta de África misma, cuyos padres se sumaron al país fundamentalmente a lo largo del siglo XX e inicios del XXI en el marco de migraciones laborales (RODRíGUEZ, 1991, p. 95-91-96, 101-102; RIVAS, 2000, p. 85). Todos proceden o están de alguna manera vinculados al mismo continente, no obstante la antigüedad de su presencia allí, el impacto del mestizaje biológico y cultural europeo previamente al traslado hasta América, su aspecto físico, o hasta sus contactos con el Islam. Así que en materia de etnohistoria afrovenezolana habría que precisar primero, cuál es la población objeto de cada estudio.

A los fines de este trabajo, se opta por definir genéricamente como afrovenezolanos a cualquiera de los integrantes de las comunidades del país que parecen ser (o se declaran) predominantemente mestizas (cultural o biológicamente) de origen africano, aclarándose en el contexto de lo escrito a cuál componente específico se hace alusión, si bien ciertamente demográficamente suele tratarse de gente cuyos ancestros penetraron al país bajo la condición de esclavos y desde la banda central de África occidental. A lo largo del último decenio ha ido cobrando mayor popularidad, hasta oficializarse en el discurso político actual, la categoría afrodescendiente, que consideramos válida, si bien en la práctica, dentro de la realidad venezolana, tiende a ser aplicable a poblaciones como las de la región del sur del Lago de Maracaibo, de Barlovento o de la costa norcentral del país que no solo se identifican como de ascendencia mestiza africana sino que además mantienen una actitud militante o reivindicativa de lo que le es propio o consideran distintivo, especialmente en luchas que tradicionalmente venían siendo asumidas por las poblaciones indígenas amerindias, como son el derecho a la tierra, al respeto a las singularidades culturales, o a un reconocimiento particular en las políticas públicas, incluida la posibilidad de regímenes de excepción dentro de la legislación vigente.

Para dar una idea del amplio espectro biológico y cultural que abarca la categoría "afrovenezolano", basta utilizar un criterio común en la antropología americanista que es la clasificación etnolingüística de los ancestros africanos conocidos por una u otra línea familiar. A juzgar por los gentilicios utilizados o por los apellidos asignados a los esclavos, que como demostró Ascencio (1984, p. 27-98) a veces identifican etnias, unidades políticas, regiones geográficas, o mercados, puertos y hasta momentos de salida o de adquisición, se podría decir que la población afrovenezolana tuvo como antepasados hablantes de idiomas clasificables dentro de las familias lingüísticas Niger-congolesas Mandé, Atlántica, Gur-Amadawa, Kwa, Volta-Niger, y Benue-Congo (tanto Bantuoide como Cross River), para el caso de los subsaharianos, y en lo que respecta a los norteños, de las divisiones Berber y Semítica del conjunto Afro-asiático Norte (no obstante que estos 
últimos ya eran hablantes del español al momento de su traslado al país).

Además de esa diversidad de origen, el reconocimiento o no de la diversidad interna -dentro del territorio venezolano- de los componentes afrovenezolanos podría incidir en las estrategias metodológicas a aplicar; en nuestra opinión, habría que considerar una escala de diferenciación que se seleccionaría dependiendo de los alcances y objetivos de la investigación, que remite a unidades territoriales y sociales, y cuya gradación está definida a partir de los rasgos (biológicos o culturales) afines tomados en cuenta. Así, por ejemplo, dentro del gran colectivo de pueblos afrovenezolanos (con o sin consciencia de sí o de militancia política), se podría abordar el caso particular del área geográfica y cultural barloventeña (escala regional), u optar por enfatizar en el enclave de Birongo (escala local), del cual quizás finalmente interese únicamente indagar sus orígenes históricos y la influencia del componente congolés o bantuoide del tronco Benué-congo, que como han demostrado algunos investigadores pareciera predominar y sería distinto al de los enclaves afrovenezolanos de origen mestizo-antillano, o a los del sur del Lago de Maracaibo. Podrían existir dentro de un colectivo determinado rasgos característicos o exclusivos (léxicos, etnográficos, genéticos, etc.) que remiten a un específico componente africano raíz predominante, pero además otros, compartidos a escala más amplia, que permiten reagruparlo junto a las demás comunidades afrovenezolanas locales, regionales o del continente.

Precisamente, la pertinencia de la etnohistoria en el estudio de estas comunidades viene dada por la posibilidad de distinguirlas a partir de esos rasgos específicos dentro del conjunto de la población venezolana en términos de cierta etnicidad, cuando conforman enclaves susceptibles de ser investigados diacrónicamente o estableciendo cortes cronológicos (mejor aún, contrastando series de cortes sincrónicos), de manera integral o enfatizando en rasgos biológicos o culturales (campos etnográficos) particulares (organización social, actividades tecno-económicas, lenguaje, medicina, religión, etc.). Los rasgos estudiados suelen tener una doble naturaleza, pues constituyen objeto de estudio en sí mismos e indicadores o marcadores para el seguimiento histórico del colectivo o de elementos específicos asociados a este.

Como ya se dijo, el reconocimiento de rasgos biológicos a los cuales se les atribuye cierto valor diagnóstico para identificar componentes étnicos africanos específicos dentro de las comunidades afrovenezolanas ha sido adelantado notablemente gracias a los trabajos de Layrisse y Wilbert (1966), Arends (1992), y Castro et al. (CASTRO DE GUERRA, ARROYO, SALZANO, CÁTIRA BORTOLINI, 2003), entre otros. Los ensayos en la búsqueda de marcadores arqueológicos han sido poco productivos dada la naturaleza perecedera de gran parte del ajuar cotidiano de los ancestros de los afrovenezolanos (según se infiere de inventarios de haciendas y cimarroneras), sus similitudes técnicas con las de los indígenas, europeos o mestizos, la adopción local de tecnologías no africanas, o la imposibilidad ética de prospectar yacimientos en donde podrían existir materiales con mayores posibilidades diagnósticas (como los cementerios); así que el abordaje arqueológico de estos colectivos hasta los momentos se ha hecho de manera indirecta, por su documentada asociación a ciertas unidades de producción coloniales o republicanas, o a los sitios de habitación utilizados por 
los dueños o por los coordinadores principales de los procesos de trabajo. Otros posibles indicadores arqueológicos tienen que ver con la impronta dejada en el paisaje, lo cual incluye ciertos patrones de asentamiento y elementos constructivos, o la ausencia absoluta (física y en la memoria oral) de centros de control o unidades residenciales utilizadas por los amos o coordinadores de tareas en pueblos afrovenezolanos de vieja data, lo cual quizás tiene que ver con un origen cimarrón de la comunidad (RIVAS, 2000, p. 87-89).

\section{El enfoque interdisciplinario y la integración de fuentes y métodos}

En un principio el abordaje etnohistórico de los componentes afrovenezolanos no tendría que diferir del seguido con respecto a las comunidades amerindias del país, especialmente, en cuanto a lo metodológico, al empleo de un enfoque interdisciplinario, el cual, sobre todo a partir de la década de los ochentas del siglo pasado, se reveló como especialmente útil para desentrañar los orígenes y transformaciones de distintas etnias venezolanas de las familias Arawak, Caribe, Chibcha, Sáliva o Warao. Tal como ha promovido UNESCO en el proyecto de reconstrucción de la historia africana (KI-ZERBO, 1982, p. 25-44), una adecuada combinación de fuentes y métodos aportados por distintas ciencias y subdisciplinas, tanto de las ciencias sociales como de las ciencias naturales, quizás permita superar el difícil reto de conocer procesos históricos en los cuales ha estado vinculado un sector de la población que durante siglos estuvo prácticamente al margen del uso de la escritura o de la posibilidad de incorporar en la documentación oficial sus propias visiones del mundo y de la Historia, por su condiciones de continua exclusión social.

La articulación de los datos aportados por las diferentes ciencias/disciplinas no sólo podría permitir superar lagunas de información sino reflexionar -siquiera por el puro gozo académico, ya que es políticamente cuestionable- sobre el tema de la historicidad o validez empírica de las versiones locales sobre esos procesos históricos, y determinar hasta qué punto constituyen otro elemento dentro del conjunto de rasgos culturales identitarios propios o si se trata de interpretaciones individuales recogidas fortuitamente por los investigadores y no necesariamente compartidas o de amplia difusión territorial. Se ha detectado, por ejemplo, que pese a lo sugerido por la biología local y por las fuentes orales, arqueológicas o historiográficas, ciertas comunidades han preferido encubrir su ascendencia afrovenezolana optando por identificarse con los componentes indígenas amerindios locales (ALTEZ, 1987; POLLAK-ELTZ, 1998, p. 249).

Idealmente los resultados de estas indagaciones académicas, aunque no necesariamente coincidan con las versiones locales, tendrían que retroalimentar a las comunidades, siquiera para fomentar el diálogo entre los saberes y subrayar el interés científico que tiene esa percepción propia. En proyectos educativos locales, ese reagrupamiento de versiones y la posibilidad de conciliarlas entre sí ha demostrado ser de gran interés para las comunidades, al menos en el caso de los amerindios, por lo cual quizás sea igualmente aplicable para los afrovenezolanos. Esto se ha intentado en el caso de 
la Parroquia Caruao, en los antes reseñados proyectos de la Universidad Central de Venezuela, bajo la forma de talleres realizados en las comunidades (La Sabana), de emisiones en radios comunitarias (Caruao), de exposiciones en escuelas (La Sabana) o en espacios especialmente habilitados para ello (Osma), o de reuniones de trabajo con los Consejos Comunales.

Tal vez la principal aplicación del reconocimiento de líneas de ascendencia a específicos colectivos africanos de origen es que facilita el estudio comparativo de poblaciones con el fin de desentrañar la lógica en el comportamiento de los contingentes desplazados a nuestro continente, verificando si su conducta, y los diferentes rasgos biológicos y culturales de los cuales probablemente fueron portadores, respondía o no a situaciones y procesos histórico-culturales cotidianamente enfrentados en África y no exclusivamente como respuestas al régimen de esclavitud. Sin embargo, añade como reto metodológico adicional, necesario, la localización de material descriptivo contemporáneo al momento de la implantación de esos africanos al país, que en lo que respecta a fuentes historiográficas y cartográficas antiguas nos remite a documentos y archivos europeos distintos a los españoles (holandeses, ingleses, franceses), e inclusive a fuentes árabes, o bien a estudios que expongan o sinteticen datos (arqueológicos, lingüísticos, biológicos, memoria oral, etc.) referidos a ese tiempo. Por otra parte, una contrastación entre el devenir de los colectivos raíces y las comunidades afrovenezolanas en donde tuvieron fuerte influencia demográfica y cultural se presta para ensayar estudios con énfasis en los procesos de cambio cultural y la influencia diferencial que pudieron haber tenido los subsecuentes contextos sociales y ambientales particulares de cada región.

La posibilidad de realizar estudios etnohistóricos de larga duración puede resultar más compleja a causa de los procesos migratorios que ha experimentado el país, sobre todo durante la segunda mitad del siglo XX. Aunque entre los descendientes de esclavos la tendencia después de la disolución del régimen de esclavitud fue a mantenerse en asentamientos cercanos a las unidades de producción (hatos, haciendas, minas) en las cuales aportaban la fuerza de trabajo, la búsqueda de mejores oportunidades laborales y en materia de acceso a servicios también los impulsó a migrar a los principales centros urbanos de sus regiones (Caracas, Maracay, Ciudad Bolívar, El Tigre, Maracaibo), constituyendo el análisis de la memoria oral y los estudios genealógicos importantes apoyos metodológicos para reconstruir las etapas más recientes de su historia. En el estado Vargas, el Puerto de La Guaira y la red de instituciones sanitarias constituyó una alternativa para muchos afrovenezolanos procedentes de la Parroquia Caruao, quienes se vieron impulsados a establecer residencia (principal o segunda residencia) en la zona central de la entidad, dada la dificultad de desplazarse diariamente a sus pueblos de origen. La conformación de redes locales de apoyo y la solidaridad interfamiliar impulsó a conformar vecindarios y hasta pequeños enclaves en donde se observa la continuidad de rasgos culturales característicos de sus áreas de procedencia. Las migraciones internas imponen también cierta cautela al abordarse el estudio de sus pueblos de origen, que tal vez tampoco se han mantenido al margen de movilizaciones locales o regionales; por ejemplo, los datos recopilados por el Proyecto de Antropología de la Parroquia Caruao registran 
desplazamientos desde el antiguo pueblo de Los Caracas hacia Osma (reactivando demográficamente la concentración local del componente afrovenezolano), desde distintos puntos del país hacia Oritapo (desplazando demográficamente a la población afrovenezolana original), o desde el caserío mirandino de Casupal hacia La Sabana (originando un enclave campesino de distinto origen dentro del asentamiento afrovenezolano precedente). Una tendencia similar se apreció durante varias décadas en el oriente del país, entre descendientes de afrovenezolanos procedentes de los enclaves afroantillanos de Paria (estado Sucre) y El Callao (estado Bolívar), quienes entre sus rasgos culturales compartían el dominio del inglés y a veces el francés (o el patuá y el inglés criollo), haciéndolos especialmente aptos para desempeñarse laboralmente en el sector petrolero, impulsándolos a residenciarse en El Tigre, el principal centro urbano próximo a las actividades industriales, trasladando consigo numerosos elementos culturales propios (festividades, gastronomía, música, idioma, etc.)³.

\section{Hacia la apropiación social de los resultados de la investigación}

Algunos aspectos críticos del discurso epistemológico postmoderno referidos al papel del investigador frente a las comunidades en donde realiza sus labores aplican también en el quehacer de la etnohistoria afrovenezolana. En un principio, se tendría que brindar facilidades para la coparticipación de las colectividades en el proceso de investigación, oportunidades para que den sus propias opiniones sobre la trascendencia de los datos, pero sobre todo -en lo posible- para aprovechar los resultados a los fines de enfrentar problemas de diferente índole, muchos de estos, por cierto, derivados de su condición de excluidos, que, en el caso de la Parroquia Caruao, han tenido que ver inclusive con un cuestionamiento foráneo a la legitimidad de su presencia en el territorio que hoy ocupan.

Por ejemplo, a juzgar por testimonios recogidos entre afrodescendientes de Osma, cuyas tierras fueron reclamadas recientemente por una compañía constructora que dice poseer títulos de propiedad anteriores (1956) a la presencia de la comunidad, la población se ha encontrado bajo la presión de demostrar -y no sólo justificar, como pisatarios- la historicidad de sus argumentos, incluso más allá de los testimonios orales, como se les reconoce a los indígenas en el marco jurídico actual. Los ancianos recuerdan que, ciertamente, la mayor parte de sus ancestros habitaban hasta 1948 en el desaparecido pueblo de Los Caracas, año en el cual fueron forzados a irse a Osma, pues aquel otro poblado sería destinado a la construcción de un leprocomio, primero, y a una conocida Ciudad Vacacional, finalmente. Los así desplazados fueron estableciéndose en la zona norte de la casa de la antigua hacienda de Osma (sector El Níspero), actualmente desaparecida; sin embargo, a raíz de un desborde del río Osma, la gente se mudó más hacia el sur, a los predios del actual pueblo, que antes estaba ocupado por los campos de cultivo. Pero no eran los primeros habitantes del lugar;

\footnotetext{
${ }^{3}$ Esta diáspora fue detectada por el Instituto del Patrimonio Cultural durante estudios de documentación de El Callao en los cuales pudimos participar a los fines de elaborar una propuesta integral (patrimonio cultural tangible e intangible) para su declaratoria como Bien de Interés Cultural de la nación.
} 
en esa zona había algunos lugareños que vivían en el valle incluso antes de la diáspora desde Los Caracas, y de hecho parte de la documentación procesada por Altez (ALTEZ y RIVAS, 2002) demuestra que hubo una secuencia de ocupaciones que se remonta a los tiempos de la Colonia. Por otra parte, si bien la empresa constructora argumenta que compró los terrenos de la desaparecida hacienda, la transferencia de la propiedad sucedió después del desplazamiento reportado en la historia oral -es decir, los osmeños estaban allí antes- y realmente nunca se había interesado en llevar a cabo desarrollos urbanos o turísticos en los años que siguieron; solo recientemente, con el auge turístico de la zona favorecido por las mejoras en las vías de comunicación terrestre es que decidió reactivar sus intereses.

Dentro de la memoria histórica oral osmeña recogida destacan dos aspectos: en primer lugar, su repetida situación como población desplazada y amenazada (primero por una imposición gubernamental, luego por las inundaciones del río, y ahora por intereses particulares externos), y por otra parte, el papel que como referente geográfico en esta historia comunitaria ha tenido la desaparecida "Casa Grande" de la hacienda, una suerte de hito que eslabona distintos momentos de su historia.

El renacimiento del interés de la constructora por los terrenos que ocupa el pueblo así como por un pequeño valle cercano que también dependía de la hacienda coincidió con la segunda etapa de investigaciones locales llevadas a cabo por el Proyecto Antropología de la Parroquia Caruao, que ya en una primera oportunidad había confirmado arqueológicamente la existencia, localización y cronología relativa de la "Casa Grande". En esta nueva fase el relevamiento planimétrico de las estructuras y su confrontación con los testimonios orales de quienes tuvieron la oportunidad de verla aún en pleno funcionamiento permitió hacer una reconstrucción aproximada de su aspecto que contó con el aval de los ancianos fundadores (figura 1). Así mismo, sus relatos facilitaron la localización de los espacios identificados con el primer poblado, en donde las excavaciones permitieron recuperar artefactos de uso cotidiano de mediados del siglo XX, es decir, contemporáneos a su establecimiento después de la expulsión de Los Caracas. Unos y otros datos a partir del año 2003 pudieron ser correlacionados con otro tipo de información, fotografías aéreas tomadas durante las décadas de 1940, 1950, 1970 y 1990, que, analizadas en conjunto, permitieron confirmar la secuencia de ocupación y de uso de la tierra relatada por los ancianos, verificar la posición, áreas de actividad. y características morfológicas de la "Casa Grande", y determinar la afinidad existente entre el patrón de asentamiento y las tipologías constructivas del viejo pueblo de Osma y del desaparecido pueblo de Los Caracas. Todo esto resultaba coherente con los relatos de los ancianos y daba una idea de cierta homogeneidad cultural entre unos y otros habitantes, "fundadores" o actuales, su identificación como los mismos actores, todo lo cual respaldaba esas versiones locales de la historia, y por ende, la legitimidad de su presencia en el lugar. 


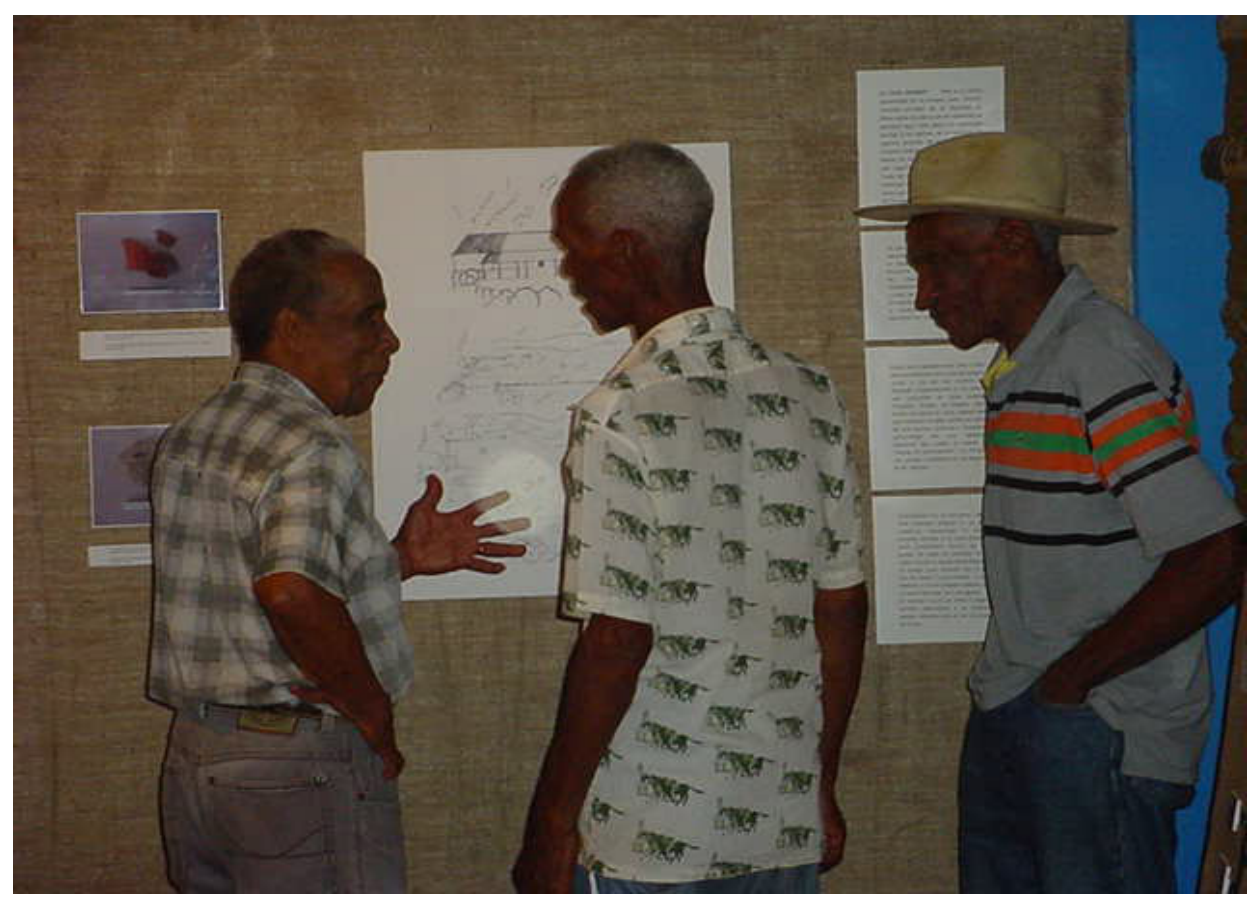

Figura 1. Ancianos fundadores del pueblo de Osma comentan el resultado del ensayo de reconstrucción arqueológica de

la Casa Grande de la hacienda, en el marco de una exposición instalada en la biblioteca de la comunidad.

Tal como sucede con los procesos de demarcación de tierras indígenas (Ley de demarcación y garantía del hábitat y tierras de los pueblos indígenas, del año 2001), aunque no les debería corresponder a los investigadores participar directamente en las gestiones locales por la titularidad de la tierra, toda la información generada por el Proyecto de Antropología de la Parroquia Caruao fue puesta a la disposición de la comunidad, para que ellos mismos, bajo sus propios criterios, decidan cómo se pudiera aprovechar. Si bien algunos pobladores, invocando los cambios jurídicos experimentados en Venezuela desde el año 1999, consideran que para hacer valer sus derechos basta aludir a su condición de pisatarios y al importante papel que tendría para su supervivencia futura garantizar el acceso a los predios del pueblo así como a las tierras cultivables periféricas, a otros les tranquiliza disponer de testimonios históricos que los respaldan; en este sentido, los estudios etnohistóricos realizados por el proyecto les han brindado acceso a datos que tal vez podrían servirles a los fines de demostrar la validez de sus argumentos. 


\section{REFERENCIAS}

ACOSTA SAIGNES, Miguel. Vida de los esclavos negros en Venezuela. Caracas: Editorial Hespérides, 1967.

ALTEZ, Yara. Todasana: el trayecto de su singular identidad. Caracas: Universidad Central de Venezuela, 1999.

ALTEZ, Yara y Pedro RIVAS. Arqueología e historia colonial de la Parroquia Caruao. Caracas: Universidad Central de Venezuela/Fondo Editorial Tropykos, 2002.

ALTEZ, Yara y Pedro RIVAS. Avances en arqueología afrovenezolana: el Proyecto Antropología de la Parroquia Caruao. Revista de Arqueología Pública, Campinas, Vol. 1, N 11, pp. 36-59, 2015.

ARENDS, Tulio. Estructura genética de la población indígena de Venezuela. Trabajo de incorporación a la Academia Nacional de Medicina 1989. Caracas: La Universidad de las Naciones Unidas, 1992.

ASCENCIO, Michelle. Del nombre de los esclavos y otros ensayos afroamericanos. Caracas: Universidad Central de Venezuela, 1984.

BRITO FIGUEROA, Federico. El problema tierra y esclavos en la historia de Venezuela. Caracas: Talleres de Mersifrica, 1973.

CASTRO DE GUERRA, Dinorah; ARROYO, Esteban; SALZANO, Francisco Mauro; CÁTIRA BORTOLINI, María. Transplanted male genomes in three venezuelan populations, Interciencia. Caracas: Asociación Interciencia, Vol. 28, № 4, pp. 197-201, 2003.

CHACÓN, Alfredo. Curiepe. Ensayo sobre la realización del sentido en la actividad mágicoreligiosa de un pueblo venezolano. Caracas: Universidad Central de Venezuela, 1979.

GUERRA CEDEÑO, Franklin. Esclavos negros, cimarroneras y cumbes de Barlovento. Caracas: Cuadernos Lagoven, 1984.

HERRERA SALAS, Jesús María. El negro Miguel y la primera revolución venezolana. La cultura del poder y el poder de la cultura. Caracas: Vadell Hermanos Editores, 2003.

KI-ZERBO, Joseph. Introducción general. In: KI-ZERBO, Joseph (director). Historia general de África. I. Metodología y prehistoria africana. Madrid: Editorial Tecnos, S.A./Organización de las Naciones Unidas para la Educación, la Ciencia y la Cultura (UNESCO), 1982, p. 23-44.

LAYRISSE, Miguel; WILBERT, Johannes. Indian societies of Venezuela: their blood group types. Caracas: Fundación La Salle de Ciencias Naturales, 1966.

MORENO, Petra Josefina; TARAZONA, Alberto. Materiales para el estudio de las relaciones interétnicas en La guajira, siglo XVIII: documentos y mapas. Caracas: Academia Nacional de la Historia, 1984. 
PÉREZ, Berta. Versions and images of historical landscape in Aripao, a maroon descendent community in Southern Venezuela. América Negra. Bogotá, N 10, pp. 129-148, 1995.

POLLAK-ELTZ, Angelina. Vestigios africanos en la cultura del pueblo venezolano. Caracas: Universidad Católica Andrés Bello, 1972.

POLLAK-ELTZ, Angelina. Presencia e invisibilidad del negro en Venezuela. Montalbán. Caracas: Universidad Andrés Bello, № 20, pp. 247-251. 1998.

POLLAK.ELTZ, Angelina. La esclavitud en Venezuela: un estudio histórico-cultural. Caracas: Universidad Católica Andrés Bello, 2000.

RIVAS, Pedro. Aproximación a la Arqueología Afrovenezolana. Boletín Museo Arqueológico de Quibor. Quíbor: Museo Arqueológico de Quibor, № 7, pp. 83-98. 2000.

RODRÍGUEZ, Omar. Contribución a la crítica del indigenismo. Caracas: Sociedad Venezolana de Arqueólogos/Editorial Abre Brecha c.a., 1991.

RODRÍGUEZ SARRALDE, Alvaro; CASTRO DE GUERRA, Dinorah; GONZÁLEZ, Mercedes; MORALES, Jorge. Frecuencia génica y porcentaje de mezcla en diferentes áreas geográficas venezolanas de acuerdo a los grupos $\mathrm{RH}$ y $\mathrm{ABO}$, Interciencia. Caracas: Asociación Interciencia, Vol. 26, № 1, pp. 8-12, 2001.

SALAS, Yolanda; GONZÁLEZ VILORIA, Norma; VELÁSQUEZ, Ronny. Bolívar y la Historia en la conciencia popular. Caracas: Universidad Simón Bolívar, 1987.

SALAZAR LUGO, Raquel; GONZÁLEZ, María; CASTRO-GUERRA, Dinorah; ARENDS. Anabel. Haplotipos de los genes BETA-A y BETA-S globulina en la población de Campoma, Estado Sucre, Venezuela. Acta Bioquímica Clínica Latinoamericana. La Plata, Vol. 40, № 2, pp. 205-211, 2006.

WILBERT, Johannes. Kinsmen of Flesh and of Blood: A Comment on Possible Socioeconomic Africanisms in Goajiro Indian Culture. Latin American Anthropology Group Contributions. Los Angeles: University of California, Vol. 1, № 1, pp. 58-66, 1976. 